\section{Public Health} Genomics
Public Health Genomics 2014;17:23-32

DOI: 10.1159/000355359
Received: June 16, 2013

Accepted after revision: August 29, 2013

Published online: November 6, 2013

\title{
Perceptions of African-American Health Professionals and Community Members on the Participation of Children and Pregnant Women in Genetic Research
}

\author{
E.M. Ngui ${ }^{\mathrm{a}} \quad$ T.D. Warner ${ }^{\mathrm{b}} \quad$ L. W. Roberts ${ }^{\mathrm{c}}$ \\ aDepartment of Community and Behavioral Health Promotion, Joseph J. Zilber School of Public Health, University of \\ Wisconsin-Milwaukee, Milwaukee, Wis., b Department of Family and Community Medicine, University of New Mexico, \\ Albuquerque, N.Mex., and 'Department of Psychiatry and Behavioral Sciences, School of Medicine, Stanford University, \\ Stanford, Calif., USA
}

\section{Key Words}

African-American · Attitudes - Children · Ethical issues .

Genetic research · Pregnant women

\begin{abstract}
Background: As genetic research gains more prominence in society, ethical concerns and the need for safeguards in the participation of children and pregnant women have increased. This study examined the perspectives of AfricanAmerican health professional and community members on genetic research involving children and pregnant women. Methods: We used a mixed-methods approach to collect and analyze survey data and qualitative data from focus groups of community members and structured interviews of health professionals. Results: We found that community members had significantly more favorable attitudes toward participation of children and pregnant women in genetic research than health professionals. Health professionals did not differ significantly from community members in their perceived understanding of genetic research. Emergent themes included limited knowledge of genetic research and distinction of biomedical research and clinical care, ethical concerns about confidentiality and potential harm, and the need to protect children and pregnant women. Participants ex-
\end{abstract}

pressed high interest and favorable attitude towards genetic research, despite limited genetic knowledge and concerns of potential harm to children and pregnant women. Some participants felt that genetic research findings could help dispel stigma and reduce discrimination, especially in mental illness. Conclusion: Findings suggest that the recruitment of participants into genetic research should directly address privacy and benefit concerns, and limited knowledge of physical and mental illness genetic research. There is a critical need to invest and engage racial/ethnic communities early, provide education on genetics, mental illness, and translate and share research findings with these communities.

(c) 2013 S. Karger AG, Basel

\section{Introduction}

Genetic research - and in particular psychiatric genetic research - has enormous social and ethical implications for low-income and racial/ethnic communities [1]. Concerns regarding genetic research are prevalent in racial/ ethnic communities and are attributed in part to a long history of racial discrimination, racism and stigma in our society [1-4]. The historical use of genetics to justify discriminatory and racist views and the misuse of genetic

\section{KARGER}

E-Mail karger@karger.com

www.karger.com/phg
(C) 2013 S. Karger AG, Basel

$1662-4246 / 13 / 0171-0023 \$ 38.00 / 0$
Dr. Emmanuel M. Ngui

Community Health and Behavioral Health Promotion/Health Disparities University of Wisconsin-Milwaukee

PO Box 413, Milwaukee, WI 53201-0413 (USA)

E-Mail Ngui@uwm.edu 
information has negatively shaped acceptance and willingness to participate in genetic research in many racial/ ethnic communities in the US [5-7]. The ramifications of genetic research permeate many aspects of the study of health disparities, including the tendency to attribute racial differences in health and health outcomes to genetics and to minimize the role of the environment in influencing these outcomes. Subsequently, many racial/ethnic communities are skeptical of genetic research and perceive the environment to be more important in determining their health and health outcomes than genetic factors. Such concerns regarding genetic research can influence overall community attitudes and perceptions of biomedical research and limit recruitment, participation and retention of participants, thereby limiting the societal impact and potential benefits of such research [2].

The perinatal period is a critical time for genetic research, including genetic screening and tissue banking. However, despite increased interest in research during the perinatal period, there is paucity of research examining ethical issues related to the recruitment of low-income minority children and pregnant women into genetic research on psychiatric and physical illness. Moreover, the long-term ethical, legal and social ramifications of participation of parents and their children in genetic research are not clear. As such, perspectives of racial and ethnic minority groups on genetic research and the ethical implications and ramifications of these studies involving minority communities are areas of significant social and public health importance.

To start to address this knowledge gap, this study examined perceptions of African-American community members and health professionals regarding the involvement of children and pregnant women in genetic research and their acceptance of allowing children and pregnant women to participate in such studies. Anecdotal evidence suggests that racial/ethnic minority providers and researchers are as skeptical of genetic research as other stakeholders and have strong ethical concerns related to genetic research $[8,9]$. Perspectives of racial/ethnic professionals are important because they usually act as formal and informal community filters or gatekeepers of information.

\section{Methods}

We used a mixed-methods approach consisting of a brief demographic and genetic research awareness survey, focus group sessions with community members and in-depth structured interviews with professionals in an urban setting. The focus group and structured interviews used identical questions covering several do- mains including: (1) participation of racial/ethnic minority children and pregnant women in genetic research, (2) ethical issues related to physical and mental health genetic research in racial/ethnic communities, (3) ownership and use of genetic information, and (4) the long-term ethical ramifications of genetic research.

\section{Focus Group Sessions}

Each of the 3 focus groups consisted of 6-12 community participants, 18 years or older, who resided in Milwaukee, Wis., USA $(\mathrm{n}=26)$. Participants were recruited from several sources, including area health care centers/clinics, public libraries, grocery store, and agencies. The sessions were conducted at community sites conveniently located for all the participants. Each participant received a USD 25 supermarket gift card, lunch and a bus ticket for participants who requested them. The sessions lasted approximately $2 \mathrm{~h}$. We included only African-American participants because our interest was on obtaining an in-depth understanding of perceptions among African-Americans and differences between community and professional members. Participants reviewed and completed an IRB-approved consent form and a brief survey containing sociodemographic, attitudes, knowledge of genetic research, and perceptions of such research.

\section{Structured Interview Sessions}

We conducted 20 interviews with African-American mental/ behavioral health, biomedical and public health professionals not directly involved in genetic research or genetic counseling services from the Milwaukee area. Participants were recruited from local professional and community networks and listings of AfricanAmerican healthcare providers. Structured interviews were used to accommodate professionals' work schedules and allowed for indepth assessment of individual perspectives without contamination or influence of views of other professionals for the ideas being expressed. The interview sessions lasted about $45 \mathrm{~min}$, were audiotaped and professionally transcribed. Participants were compensated USD 50 for their time and effort.

\section{Measures}

Willingness to participate was assessed using the question: 'Would you be willing to enroll your child or children in a genetic research study? Why or why not?' For participation of pregnant women, we used the question: 'Would you be willing to enroll pregnant women in a genetic research study? Why or why not?' Both questions were followed with prompts asking 'what are your main (a) concerns, (b) benefits regarding participation of (1) AfricanAmerican children, and (2) pregnant women in genetic research.'

Analysis of survey data was conducted using Stata 12 SE software. Comparisons of community members and health professional's survey responses were done using $\chi^{2}$ tests. We audiotaped and transcribed verbatim the focus group and structured interview discussion. The data were managed using Atlas ti qualitative software. Thematic analysis of transcripts was guided by the approach described by Braun and Clarke [10]. Relevant themes in the transcript text of each focus group session were highlighted and margin coded. To validate the thematic coding, 2 members of the research team analyzed the transcripts independently and then met to resolve any differences by consensus. Another member of the research team independently analyzed the transcripts and provided feedback on the emerging themes. Saturation was achieved when no new themes emerged from analysis of the focus groups discussions. 
Table 1. Characteristics of health professional and community member participants

\begin{tabular}{|c|c|c|c|c|}
\hline & $\begin{array}{l}\text { Health professionals } \\
(\mathrm{n}=20)\end{array}$ & $\begin{array}{l}\text { Community members } \\
(\mathrm{n}=26)\end{array}$ & Cohen's d & $\mathrm{p}$ \\
\hline Age in years & $45.3 \pm 9.95$ & $43.2 \pm 13.81$ & 0.17 & 0.141 \\
\hline Highest education level completed ${ }^{a}$ & $4.75 \pm 0.55$ & $2.42 \pm 0.81$ & 3.28 & $<0.001$ \\
\hline Female gender & $80 \%$ & $58 \%$ & $22^{*}$ & 0.128 \\
\hline Currently employed & $100 \%$ & $40 \%$ & $60^{*}$ & $<0.001$ \\
\hline Total household income USD $>35,000 ?$ & $100 \%$ & $31 \%$ & $69^{*}$ & $<0.001$ \\
\hline Ever asked to have a genetic test & $45 \%$ & $8 \%$ & $37^{*}$ & $<0.001$ \\
\hline Ever actually got a genetic test (if ever asked) & $60 \%$ & $6 \%$ & $54^{*}$ & $<0.001$ \\
\hline Took high school course with genetics topic & $60 \%$ & $31 \%$ & $29^{*}$ & $<0.05$ \\
\hline Took college course with genetics topic & $70 \%$ & $19 \%$ & $51^{*}$ & $<0.01$ \\
\hline Told by doctor/psychologist they had mental illness & $5 \%$ & $33 \%$ & $28^{*}$ & $<0.05$ \\
\hline Interested in being contacted about genetic research & $55 \%$ & $83 \%$ & $28^{*}$ & $<0.05$ \\
\hline Has biological relative with mental illness (yes) & $35 \%$ & $48 \%$ & $13^{*}$ & 0.380 \\
\hline
\end{tabular}

Values are means $\pm \mathrm{SD}$, unless indicated otherwise. ${ }^{\text {a }}$ Education level range: $1-5=$ less than high school-some graduate education (Masters/PhD) with or without degree. ${ }^{*} \mathrm{p}_{1}-\mathrm{p}_{2}$.

\section{Results}

\section{Characteristics of Participants}

As shown in table 1, the overall sample consisted of 46 participants with $57 \%(n=26)$ of them in the focus groups and $43.4 \%(\mathrm{n}=20)$ in the professional structured interviews. The mean age was 45 years (range 27-68 years) among the professionals and 43 years (range 21-68 years) for community members. As expected, professionals were more likely to have college or higher education compared to community members who were more likely to have high school level education. Professionals also were more likely to have had high school or college courses in genetics compared to community members. Over half of the participants in both groups were female, with more male participants in the professional group (80\%). A significantly greater proportion of professionals were employed, had incomes USD $>35,000$, had ever been asked to have a genetic test, or got a test if asked, and took high school or college courses with genetic topics than community member group. The proportion of community members who had ever been told they had a mental illness was over 6 times that of professionals (33 vs. 5\%). Compared to health professionals, the proportion of community members interested in being contacted about genetic research was significantly greater. The proportions reporting having a relative with mental illness did not differ significantly between the 2 groups.

Perception of Participation of Children and Pregnant Women in Genetic Research
Community members and professionals did not differ significantly in their perception of the importance of medical or genetic research and in their comfort discussing views on genetic research (table 2). The groups, however, differed in their general attitude towards genetic research involving children or pregnant women and in their willingness to allow children to participate in genetic research, with more community members reporting more favorable views than health professionals. Both groups did not differ significantly in their overall rating of their knowledge of genetics.

\section{Quantitative Survey Results}

Health professionals and community members reported divergent views regarding the participation of children and pregnant women in genetic research. Health professionals were more likely than community members to have unfavorable or very unfavorable attitudes and disproportionately more likely to be not sure about the participation of children in genetic research (fig. 1). As shown in figure 2, health professional (40\%) were disproportionately more likely than community members (8\%) to have unfavorable or very unfavorable attitudes towards participation of pregnant women in genetic research. About half of the community members were not sure compared to $40 \%$ of health professionals. Similarly, the proportion of community members who had either favorable or very favorable attitude towards the participation of women in genetic research was twice that of health professionals. 


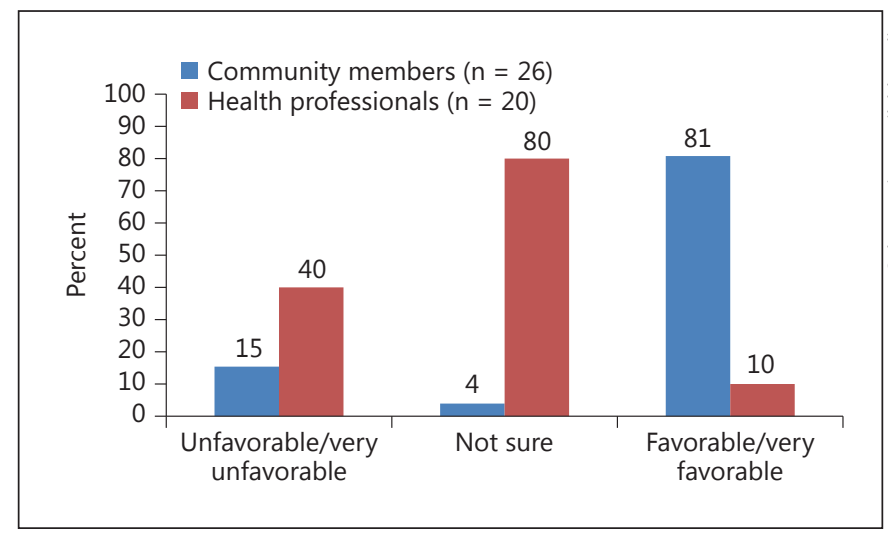

Fig. 1. General attitude towards genetic research involving children among community members and health professionals.

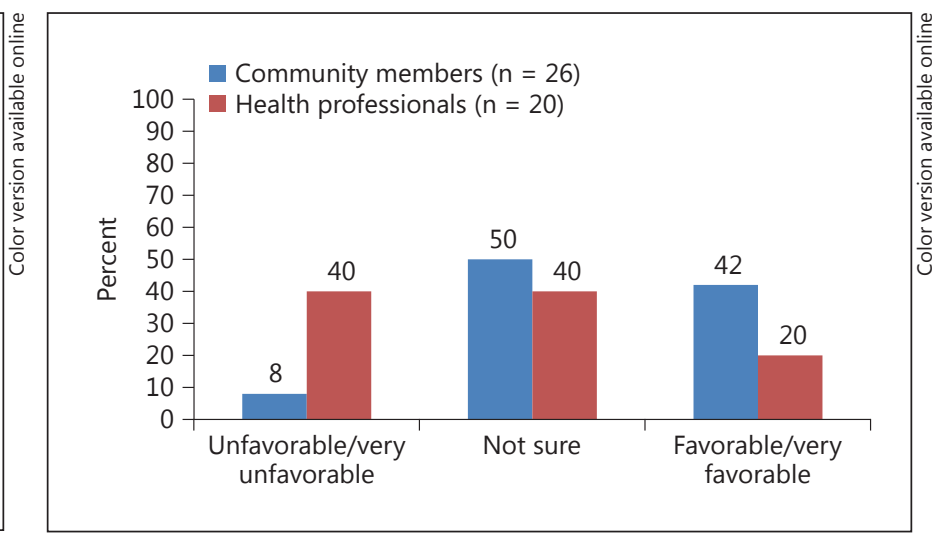

Fig. 2. General attitude towards genetic research involving pregnant women among community members and health professionals.

Table 2. Comparison of health professional and community member participants' perceptions of genetic research among African-Americans

\begin{tabular}{|c|c|c|c|c|}
\hline Survey question & $\begin{array}{l}\text { Health } \\
\text { professionals } \\
(\mathrm{n}=20)\end{array}$ & $\begin{array}{l}\text { Community } \\
\text { members } \\
(\mathrm{n}=26)\end{array}$ & Cohen's d & $\mathrm{p}$ \\
\hline How important is genetic research ${ }^{\mathrm{a}}$ & $3.50 \pm 0.76$ & $3.85 \pm 0.37$ & 0.65 & 0.114 \\
\hline General attitude on genetic research involving children ${ }^{b}$ & $2.75 \pm 0.85$ & $3.31 \pm 0.74$ & 0.72 & $<0.05$ \\
\hline General attitude on genetic research involving pregnant women ${ }^{\mathrm{b}}$ & $2.70 \pm 0.66$ & $3.85 \pm 1.35$ & 1.05 & $<0.01$ \\
\hline Ever participated as subject in medical research ${ }^{\mathrm{e}}$ (yes) & $25 \%$ & $8 \%$ & $17^{*}$ & 0.213 \\
\hline Ever offered chance to participate in medical research ${ }^{\mathrm{e}}$ (yes) & $35 \%$ & $15 \%$ & $20^{*}$ & 0.169 \\
\hline Willing to allow child to participate in genetic research ${ }^{\mathrm{e}}$ (yes) & $47 \%$ & $83 \%$ & $36^{*}$ & $<0.05$ \\
\hline
\end{tabular}

All values are means $\pm \mathrm{SD}$, unless indicated otherwise. Scales: ${ }^{\mathrm{a}} 1-4=$ Not important at all - extremely important. ${ }^{\mathrm{b}} 1-4=\mathrm{Very}$ unfavorable to very favorable. ${ }^{\mathrm{c}} 1-5=$ Not comfortable at all - extremely comfortable. ${ }^{\mathrm{d}} 1-5=$ Poor - excellent. ${ }^{\mathrm{e}} 0-1=$ No, yes. ${ }^{*}$ p $1-\mathrm{p} 2$.

\section{Qualitative Focus Group and Interview Findings}

Genetic Research Involving Children

The results show an ambivalence or reluctance of enrolling children in genetic research. Although a few participants indicated willingness to enroll children, most of the parents were guarded qualifying their responses with the words, 'it depends on...' Figure 3 shows some of the key issues identified by participants as determinants of whether to allow their children to participate. The most frequently mentioned factors included: parental duty to protect children (overarching theme), type of study, level of invasiveness of procedures, safety/harm (e.g. pain), child's comfort, benefits to the child or family, being well informed and knowledgeable about genetics, and time commitment as important factors likely to influence their decision to allow their child to participate in genetic research.

Parental Duty to Protect Children from Harm. An overarching theme among participants was the sense of responsibility for protecting children and pregnant women from harm. All the parents felt that they had a moral and ethical duty to protect their children from harm. Parents would not readily allow their children to participate without being well informed about the study and what the procedures would entail. The overwhelming consensus was that parents have a moral, ethical and societal obliga- 
Fig. 3. Themes associated with participation of children in genetic research.

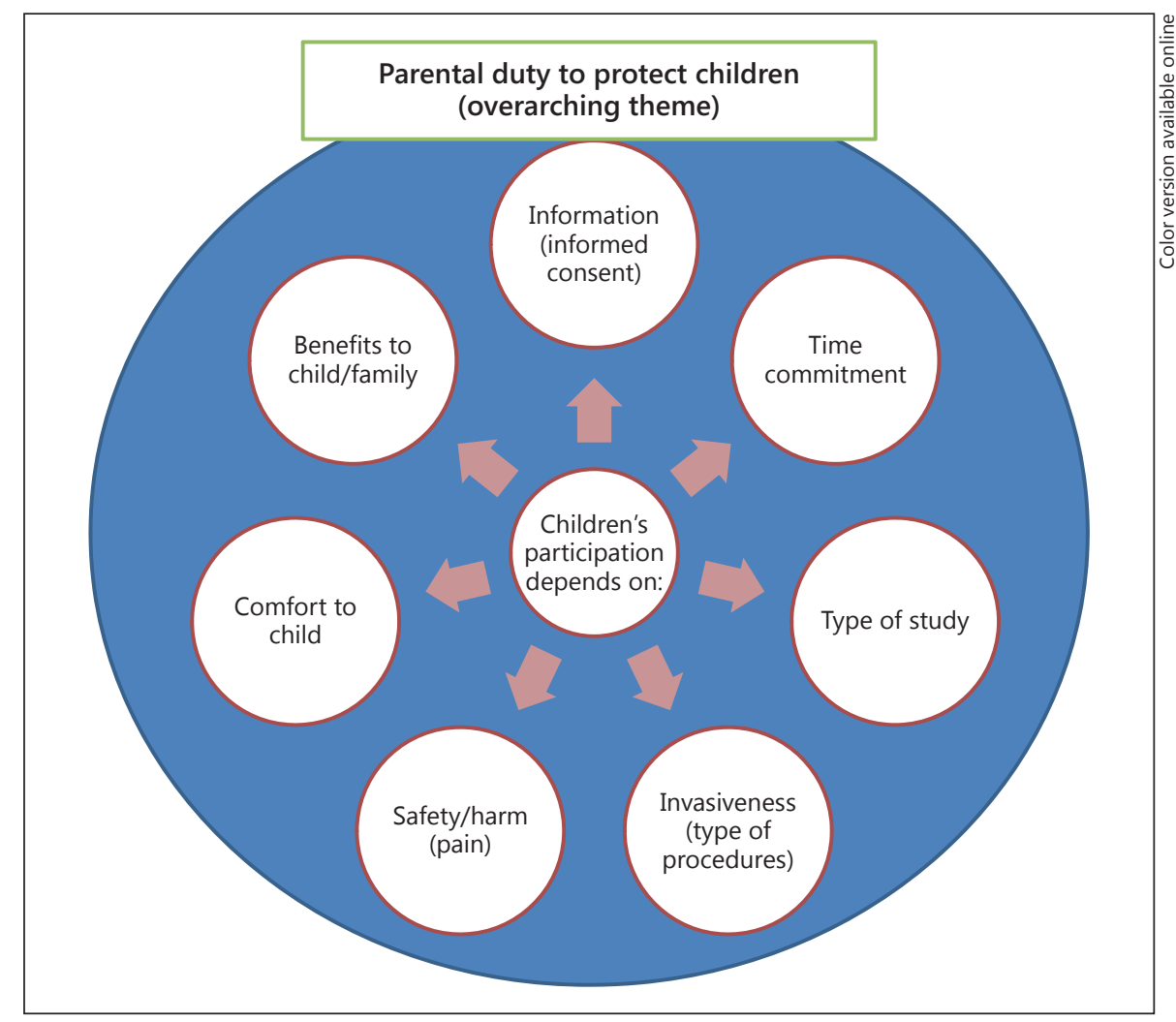

tion and duty to protect their children from harm and to advocate on behalf of their children.

Participants observed that they were responsible for their children's protection and, therefore, would need to know, evaluate and make decisions about such research because children may not understand or have the capacity to comprehend different aspects of genetic research. Participants were aware that the parental role of protecting their children from harm would vary depending on the child's age. The duty to protect was much stronger for younger children than young adults. Some participants reported willingness to consider enrolling their children depending on the children's own preference as long as safety was not an issue. One participant stated:

I would only allow my child to participate if he was at the age where I thought he could make a rational, valid decision about whether he was helping. And he wanted to do that on his own. It would be strictly up to him. If he wanted to do it, I wouldn't be the idiot that said, 'No, you can't do it.' As long as I knew he was being well-treated, it was safe, and there would be no side effects from any adverse experimentation.

Other participants observed that it would also depend on their child's understanding of the research, consenting process, and overall benefits to the child or immediate family members rather than societal benefits or altruistic reasons. Participants, for example, stated they would be willing to allow children to participate if the research was on a disorder that their child has (e.g. sickle cell) or if the research could result in early diagnosis and treatment of a health condition.

Type of Study. Willingness to enroll children would also depend on the type and scope of the study. Participants distinguished genetic research from other forms of behavioral studies involving observations and surveys or interviews. The type of study was identified as a key determinant of parental willingness to allow children to participate in genetic research. Moreover, the type of study was also related to the level of invasiveness involved in the study.

Invasiveness of Study. While many parents indicated that they would consider allowing children to participate, almost all of them qualified this decision in terms of how invasive the study procedures would be, how informed they were about the procedures and whether they would be together with their children. Several participants stated that they would allow their children to participate but only after learning more about the study, reviewing the 
consent and what types of bio specimens would be collected and what methods would be used. For most parents, there was an overall aversion to procedures that involved drawing blood or piercing the skin. One participant observed:

Well, for the children...like, my daughter's terrified of needles. So I would say no if there's a lot of needles involved, and if she had to be put-out for any kind of study, I wouldn't do that.

Another added:

You're talking about a child. And I don't know if I want adults experimenting on children like that.

One participant summed parental responsibility to protect as:

I don't know, I guess I am just the protective kind of mother. So, up to a certain age I agree with Ms. B totally, up to a certain age, I would want to filter everything that came to them from the outside.

Information/Informed Consent. The need to be informed about the research and the consenting process, particularly what will be done, what specimens will be collected and how were major factors in the parental decision-making process about their children's participation in genetic research. Words such as 'more concrete information, get that information, knowing exactly, have a lot more information, etc.' summed up the desire by participants to be well informed about the study so that they can make informed decisions about enrolling their children in genetic research. Participants talked about wanting to know, to understand and to be informed about the study before deciding on enrollment of children. One participant stated:

I think with anything, if you were talking about me, for myself or kids, I would read the consent, if I could possibly understand it.

Comfort. The child's levels of physical, psychological and emotional comfort were also mentioned as important factors that would influence parental decision to allow children to participate in genetic research. Comfort was associated with the parent's protective role, and invasiveness of the study. Participants, however, also discussed comfort from their children's perspective, for example, whether or not the children were comfortable with the decision to participate and the procedures they would undergo. Participants were less inclined to indicate that they would allow children to participate if they felt that the study would be uncomfortable to their children. Invasiveness was also associated with types of questions children are asked and their comfort not just the biological specimen/samples collected.
Speaking for my kids, I don't even know how much they would understand um what's going on. I don't know how personal it would get... For them, some of the questions can be a little, I'm sure, can get intense. So I don't know if it's necessary for them to have to go through something intense. And how much they would understand how much is going on and again I'm not sure what it [genetic research] would include. I don't know if I'd want to put my child or any of my kids through something that I don't know what to expect or what it would include. I'd definitely have to have a lot more information before I could make that kind of decision for my children.

Time Commitment. The amount of time needed to participate in genetic research was cited as an important factor. Participants appeared to be less willing to participate in genetic studies that require a large amount of time by the child and the parents. Participation in such studies could interfere with other commitments and obligations for work or school.

Overall, professionals and community members were more guarded and less certain about enrolling children in genetic research. Both groups wanted to be more informed about the study, its purpose, scope and level of invasiveness before making the decision as to whether to enroll or not enroll. Concerns about involving children in genetic research centered on the parental responsibility to protect their children, duty not to harm them and an understanding that children depend on parents to play this role of being their 'voice' in such decisions. Despite the general concerns, participants were willing to consider enrolling children if their concerns were addressed and the research was pertinent and beneficial to their child and family.

\section{Genetic Research Involving Pregnant Women}

As shown in figure 4, willingness to enroll pregnant women in genetic research centered on 6 major themes: (1) type of study, (2) invasiveness of procedures, (3) maternal and fetus safety, (4) information and informed consent, (5) vulnerability, and (6) maternal autonomy (choice) to make their own decisions.

Type of Study. Participants willingness to enroll pregnant women depended on the type of study involved. Similar to the enrollment of children, most indicated that they would be more willingness for pregnant women to enroll in behavioral observational studies involving surveys or interviews than more intrusive studies. Participants closely associated concerns related to the type of study to the level of invasiveness of the study procedures.

Invasiveness of Procedures. Participants also expressed more reluctance to enroll pregnant women in more invasive than less invasive studies. One participant noted:
Ngui/Warner/Weiss Roberts 


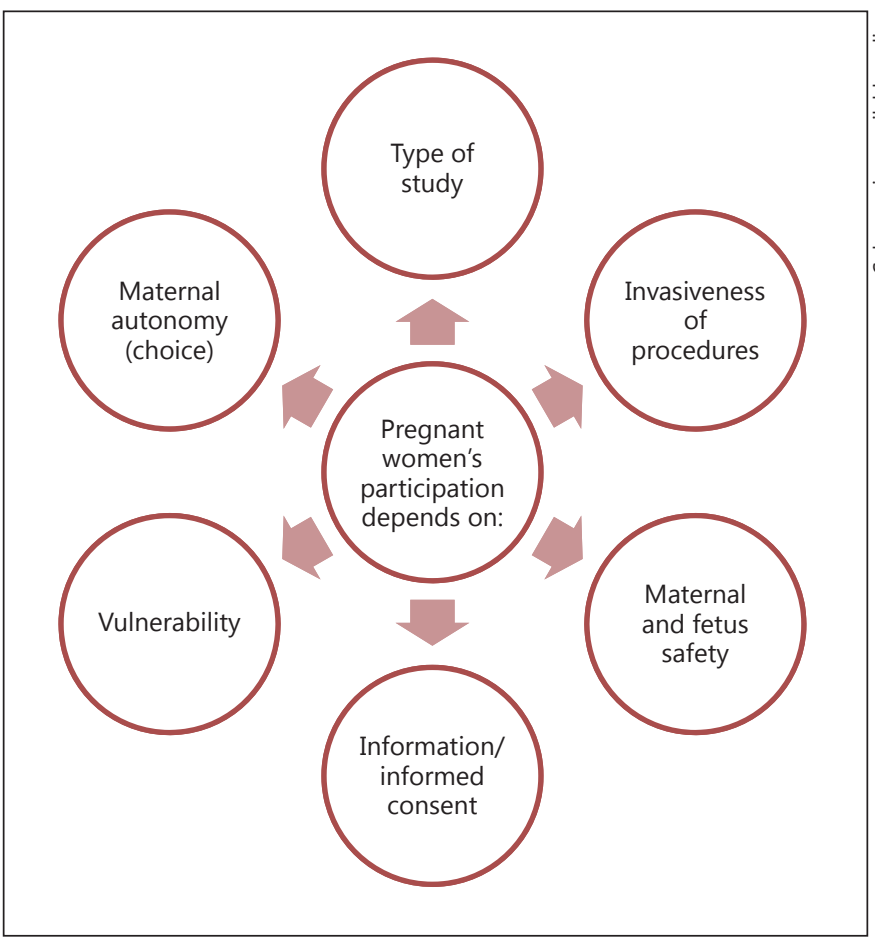

Fig. 4. Themes associated with participation of pregnant women in genetic research.

I would be leery of that just because now there's an unborn child, and you don't know all the risks. Depending on the research, and if it's something where you're just asking questions or doing things like that - but if we're testing drugs or procedures - things like that - that puts in jeopardy two people instead of one, so...

Most of the concerns with invasiveness were related to increased risk exposure and stress to the mother and unborn child.

Pregnant women, boy that really depends. Once again it goes back to that invasive question. But the one thing I would be concerned about depending on the history of the pregnant woman I would be concerned if whatever type of research activity would add additional stress to the stress of the pregnancy and lead to any complications. I would need more information to fully answer that one.

Maternal and Fetus Safety. Concerns for the safety of the fetus and to a lesser extent to the mother were the major reasons participants were reluctant to enroll pregnant women. Several participants indicated that the same safeguards for children apply to pregnant women. We note that concerns of the mother's health and wellbeing were not as strong as those related to preventing any harm to the fetus. One participant summed the concerns as:

Perception of Participation of Children and Pregnant Women in Genetic Research
I don't think I would want pregnant women, because, I don't know if enough information is available on how doing genetic research on pregnant women might affect the fetus. So, I guess I would probably not encourage it... I would be real concerned that there might be harm. There might be harm done to a child or the fetus of a pregnant woman. I don't have enough information, I think to make a real clear answer. I don't know enough about what has been done or consequences of a possible dual effect for children or pregnant women.

Participants were more focused on the safety of the unborn baby.

I think if they feel strongly one way or another about research then I'm okay with that. Again as long as the baby or the mother are never in any harm or anything you know. Then I'm okay with that because as an adult I think they can make a decision, hopefully, they can make a good decision about research for them and their child. ... But I would express my concerns that I would be nervous if she was pregnant, and what harm would it do to the baby - and to her.

Information/Informed Consent. The need for the women to be well informed and knowledgeable of the study, what it would entail and the risks and benefits involved were common concerns. This was reinforced by terms such 'as long as they are aware, want to know, really or truly understood, could explain what they are getting into, get informed, etc.'

For pregnant women, as long as they were able to truly understand or at least have an advocate there, to say, Yes, this good to do or No, it is not good to do. I would not want to exploit those who might not be as educated or whatever. If they understood it totally and then said yes, just make sure there was someone available to answer questions that they may have. If they understand it, yes.

Vulnerability. Overall, most of the concerns regarding participation of pregnant women centered on this population being a vulnerable population and at increased risk of harm or abuse and, therefore, needing extra safeguards. A few participants described vulnerability in terms of fear of exploitation (e.g. harm of sterilization). Participants seemed to struggle with balancing the autonomy of pregnant women as adults who can make their own decisions and the potential effects of their choices on the fetus.

Maternal Autonomy (Choice). Most participants, however, reported that women were adults and could, therefore, make their own decisions regarding participation in genetic research. One summed it as:

Again, that's up to the individual. If she said yes, and even if she was my wife, and I didn't want her to do, I'd have to go along with it. It's her body - her choice.

Other participants agreed with some observing that this was 'her choice,' 'it's her body, 'That's her decision.' 
Participants acknowledged that autonomy and the personal decision-making capabilities of pregnant women. As adults, these women can make their own decisions regarding participating in research, however, this autonomy need to be balanced with the health and well-being of the fetus.

\section{Discussion}

In this study, we examined perspectives of AfricanAmerican community members and health professionals towards genetic research involving children and pregnant women, populations that have been identified as having greater potential vulnerability than others in research situations. Both African-American community members and health professionals indicated the importance of engaging the community early in the process of research and of sharing study findings with the community as a way of building trust. In this study, the personal willingness to participate in genetic studies as expressed by the individuals we queried was based largely on personal or family benefits in addition to societal altruism. This finding is consistent with other studies that show participation in genetic research including biobanks [11], direct-to-consumer personal genome testing [12, 13] and disease/condition-specific studies [14] is motivated by individual, family and altruistic reasons [15]. In addition to societal benefits, researchers may need to especially consider and accurately frame the anticipated benefits of genetic research for individual or family members when enrolling African-American children. This 'best practice' may be applicable to biomedical research involving African-American volunteers as well. For many participants, the immediate benefits appear to be more important in their decision-making regarding participation than other general concerns. Researchers will need to provide concrete and clear information about the research to parents, so that they can make informed decisions about their children's enrollment into such studies. Participants valued being engaged early in the research and making the research findings and their implications accessible and understandable to the community. Exposure to genetic information and referral by health providers contribute to some of the ethnic differences in knowledge and attitude towards genetic testing (e.g. breast cancer) [16].

We found that African-American community members and health professionals are interested in and value genetic inquiry but also have concerns regarding genetic studies. They also perceive themselves as having limited knowledge of genetics research [11]. This finding is consistent with prior work showing positive attitudes towards genetic research [17] for many conditions, including colon cancer [18], breast cancer [19], diabetes, hypertension, and alcoholism [20]. In this novel project engaging African-American individuals, we found major concerns related to the participation of children and pregnant women in genetic research. There was much consensus among community members and professionals on the need to protect children from harm and ensure that the research is conducted in an informed and ethical manner. Participants were especially concerned about the potential harm to children, pregnant women and their community from genetic studies or intervention. The concerns found in this study regarding the potential harm of genetic research are consistent with those found in other studies [21-28] including studies of African immigrants in the US [29]. Furr [22], for example, found that African Americans are more likely than whites to perceive genetic research as harmful to society. In another study, African-American individuals perceived fewer potential benefits and heightened awareness of how information from genetic research could increase racial discrimination. We note that in spite of the enactment of the Federal Genetic Information Nondiscrimination Act (GINA), which provides protection against discrimination in employment or health care based on genetic information, these concerns persist even among AfricanAmerican nurses [30]. However, we are not aware of our study participant's degree of awareness of the protections provided by GINA.

In our study, participants felt that pregnant women should be accorded their full rights as adults and that they can and should make decisions about their own willingness to participate in genetic research. Still, there was an overall agreement that investigators should safeguard the health and well-being of the fetus as well as the woman's health and well-being. Our findings regarding balancing the needs of both the fetus and the mother suggest the importance of distinct strategies to address risks, benefits, and ethical concerns related to women of reproductive age, a topic that has spurred considerable controversy $[31,32]$. Our results further highlight the need for culturally appropriate strategies to increase knowledge of genetics and all forms of genetic inquiry in the AfricanAmerican community.

As expected, we found a greater divergence of opinion regarding the participation of pregnant women than of children, with community members expressing more fa- 
vorable opinions than those of health professionals. The underlying reasons for the greater acceptance by community members are not clear and highlight the need for additional studies with a larger and more ethnically diverse and representative sample than was possible in our project. The participants' narrative responses reflected increased awareness of risks, procedures, benefits, and ethical concerns among the health professionals. Interestingly, although professionals were more likely to report that they had taken courses in high school or college that covered genetic topics, they perceived their knowledge of genetics as limited. Powell-Young and Spruill [30] found a significant relationship between increased levels of education and increased negative perceptions of potential misuse of genetic research information among Black nurses. Indeed, both community members and health professionals perceived their knowledge of genetics to be insufficient, suggesting the value of public and professional education in this emerging area.

A major strength of this study is its mixed-methods approach and its highly engaged and unique study population. To our knowledge, this is the first study to examine perceptions of community members and health professionals on genetic research involving children and pregnant women specifically. Some limitations of the study include difficulty generalizing the findings to other settings or ethnic groups because of the small and homogeneous sample.

In conclusion, we found remarkable willingness, receptiveness and congruity of perspectives amongst 2 stakeholder groups with respect to genetic research participation by children and pregnant women. These stakeholder groups were previously assumed to hold divergent views. The study findings highlight several important educational and policy needs. First, the findings suggest the need for culturally appropriate strategies to increase knowledge of genetics, genetic research and other biomedical research in the African-American community. Second, the findings highlight the need for strategies to address risks, benefits and ethical concerns related to participation of children and pregnant women in genetic research. Third, our findings also suggest the importance and need for active engagement and participation of the African-American community in genetic research, to increase racial/ethnic diversity of participants and generalizability of genetic research findings to racial/ethnic groups. Finally, strategies aimed at increasing participation of African-American and other racial/ethnic minority groups in genetic and biomedical research need to be complimented with concerted and purposeful strategies to share the research findings with the affected communities.

\section{Acknowledgements}

The authors greatly acknowledge the contributions of Melinda Hantke, Chelsea Hamilton, Sherry Olson-Ngui, Ann Tennier, Krisy Edenharder, Sebastian Ssempijja, PhD and Jinger Hoop, MD for their invaluable assistance in the conduct of this project. This research was supported by grant NIMH3R01MH074080 from NIMH and NHGRI and NIMH3R01MH074080-03S1 (supplement) from the NIMH. The content is solely the responsibility of the authors and does not represent official views of the NIMH or NHGRI. The study was approved by Institutional Review Boards of Stanford University, University of New Mexico and the Medical College of Wisconsin.

\section{References}

1 Thomas SB, Fine MJ, Ibrahim SA: Health disparities: the importance of culture and health communication. Am J Public Health 2004; 94: 2050.

$>2$ Weiss JO, Allen L, Marche-Escola S, Savoy M, Rosemary, Yang S: Consumer perspectives on genetic testing, research and services for ethnoculturally diverse populations. Community Genet 1998;1:118-123.

73 Dukepoo FC: Genetic services in the new era: Native American perspectives. Community Genet 1998;1:130-133.

4 Krieger N: Stormy weather: race, gene expression, and the science of health disparities. Am J Public Health 2005;95:2155-2160.

Perception of Participation of Children and Pregnant Women in Genetic Research
5 Royal C, Baffoe-Bonnie A, Kittles R, Powell I, Bennett J, Hoke G, Pettaway C, Weinrich S, Vijayakumar S, Ahaghotu C, Mason T, Johnson E, Obeikwe M, Simpson C, Mejia R, Boykin W, Roberson P, Frost J, Faison-Smith L, Meegan C, Foster N, Furbert-Harris P, Carpten J, Bailey-Wilson J, Trent J, Berg K, Dunston G, Collins F: Recruitment experience in the first phase of the African American Hereditary Prostate Cancer (AAHPC) study. Ann Epidemiol 2000;10(suppl 8):S68S77.

$\checkmark 6$ Hoyo C, Reid ML, Godley PA, Parrish T, Smith L, Gammon M: For the patient. Improving participation of African-American men in research studies. Ethn Dis 2003;13: 547-548.
7 Sankar P, Cho MK, Condit CM, Hunt LM, Koenig B, Marshall P, Lee SS, Spicer P: Genetic research and health disparities. JAMA 2004;291:2985-2989.

$>8$ Edwards KL, Lemke AA, Trinidad SB, Lewis SM, Starks H, Snapinn KW, Griffin MQ, Wiesner GL, Burke W; GRRIP Consortium: Genetics researchers' and IRB professionals' attitudes toward genetic research review: a comparative analysis. Genet Med 2012;14: 236-242.

-9 Campbell E, Ross LF: Attitudes of healthcare professionals and parents regarding genetic testing for violent traits in childhood. J Med Ethics 2004;30:580-586. 
10 Braun AG, Clarke V: Using thematic analysis in psychology. Qual Res Psychol 2006;3:77101.

-11 Streicher SA, Sanderson SC, Jabs EW, Diefenbach M, Smirnoff M, Peter I, Horowitz CR, Brenner B, Richardson LD: Reasons for participating and genetic information needs among racially and ethnically diverse biobank participants: a focus group study. J Community Genet 2011;2:153-163.

12 Wasson K, Sanders TN, Hogan NS, Cherny S, Helzlsouer KJ: Primary care patients' views and decisions about, experience of and reactions to direct-to-consumer genetic testing: a longitudinal study. J Community Genet 2013, E-pub ahead of print.

13 Rahm AK, Feigelson HS, Wagner N, Le AQ, Halterman E, Cornish N, Dearing JW: Perception of direct-to-consumer genetic testing and direct-to-consumer advertising of genetic tests among members of a large managed care organization. J Genet Couns 2012;21: 448-461.

14 Halbert CH, Gandy OH Jr, Collier A, Shaker $\mathrm{L}$ : Intentions to participate in genetics research among African American smokers. Cancer Epidemiol Biomarkers Prev 2006;15: 150-153.

15 Facio FM, Brooks S, Loewenstein J, Green S, Biesecker LG, Biesecker BB: Motivators for participation in a whole-genome sequencing study: implications for translational genomics research. Eur J Hum Genet 2011;19:12131217.

16 Hughes C, Gomez-Caminero A, Benkendorf J, Kerner J, Isaacs C, Barter J, Lerman C: Ethnic differences in knowledge and attitudes about BRCA1 testing in women at increased risk. Patient Educ Couns 1997;32:51-62.
17 Fullenkamp AN, Haynes EN, Meloncon L, Succop P, Nebert DW: Perceptions of genetic research in three rural Appalachian Ohio communities. J Community Genet 2013;4:917.

18 Satia JA, McRitchie S, Kupper LL, Halbert $\mathrm{CH}$ : Genetic testing for colon cancer among African-Americans in North Carolina. Prev Med 2006;42:51-59.

19 Lipkus IM, Iden D, Terrenoire J, Feaganes JR: Relationships among breast cancer concern, risk perceptions, and interest in genetic testing for breast cancer susceptibility among African-American women with and without a family history of breast cancer. Cancer Epidemiol Biomarkers Prev 1999;8:533-539.

20 Marshall VJ, Kalu N, Kwagyan J, Williams C, Taylor RE, Scott DM: Perceptions about genetic testing for the susceptibility to alcohol dependence and other multifactorial diseases. Genet Test Mol Biomarkers 2012;16:476-481.

-21 Thompson HS, Valdimarsdottir HB, Jandorf L, Redd W: Perceived disadvantages and concerns about abuses of genetic testing for cancer risk: differences across African American, Latina and Caucasian women. Patient Educ Couns 2003;51:217-227.

22 Furr LA: Perceptions of genetics research as harmful to society: differences among samples of African-Americans and EuropeanAmericans. Genet Test 2002;6:25-30.

23 Achter P, Parrott R, Silk K: African Americans' opinions about human-genetics research. Politics Life Sci 2004;23:60-66.

24 Bates BR, Lynch JA, Bevan JL, Condit CM: Warranted concerns, warranted outlooks: a focus group study of public understandings of genetic research. Soc Sci Med 2005;60:331344 .
25 Bussey-Jones J, Henderson G, Garrett J, Moloney $\mathrm{M}$, Blumenthal C, Corbie-Smith G: Asking the right questions: views on genetic variation research among black and white research participants. J Gen Intern Med 2009; 24:299-304.

26 Hamilton LA, Aliyu MH, Lyons PD, May R, Swanson CL Jr, Savage R, Go RC: AfricanAmerican community attitudes and perceptions toward schizophrenia and medical research: an exploratory study. J Natl Med Assoc 2006;98:18-27.

27 Corbie-Smith G, Thomas SB, St. George DMM: Distrust, race, and research. Arch Intern Med 2002;162:2458-2463.

28 Corbie-Smith G, Thomas SB, Williams MV, Moody-Ayers S: Attitudes and beliefs of African Americans toward participation in medical research. J Gen Intern Med 1999;14:537546.

29 Buseh AG, Underwood SM, Stevens PE, Townsend L, Kelber ST: Black African immigrant community leaders' views on participation in genomics research and DNA biobanking. Nurs Outlook 2013;61:196-204.

30 Powell-Young YM, Spruill IJ: Views of Black nurses toward genetic research and testing. J Nurs Scholarsh 2013;45:151-159.

31 Schenker JG, Eisenberg VH: Ethical issues relating to reproduction control and women's health. Int L Gynaecol Obstet 1997;58:167176.

32 Robertson JA: Embryo stem cell research: ten years of controversy. J Law Med Ethics 2010; 38:191-203. 